\section{Neurotransmitters and Epilepsy}

\section{Kenia Pardo*}

Department of Cell and Molecular Biology, Guadalajara University, Mexico

\section{Editorial}

I studied my $\mathrm{PhD}$ in Biomedical Sciences specialized in Neurosciences in the University of Guadalajara, University Center for Health Sciences, earning Honorable Mention in the exam to obtained the degree. As a result of my Doctoral project I got four articles published in various international journals, one of which I am the first author and I have presented results in three posters at different International Congresses. During that period, my studies focused on determining the contribution of chemical neurotransmission systems on high frequency oscillations associated with epileptogenic processes in the laboratory of Neurophysiology and Neurochemistry in University Center of Biological and Agriculture Sciences in University of Guadalajara, where I worked with Dr. Laura Medina-Ceja who was my mentor. In her laboratory we develops electrophysiology techniques for detection of high frequency oscillations, stereotaxic surgery for implanting electrodes and guide cannula, microdialysis and HPLC techniques, on-line measurements of glutamate by fluorescence, and implementation of different experimental models of epilepsy (acute and chronic). We obtained very interesting results on the modulation of neurotransmitter systems in the high-frequency oscillations $(250-500 \mathrm{~Hz})$ involved in hippocampal epileptogenesis, especially in temporal lobe epilepsy. Temporal lobe epilepsy (TLE) is the most common type of partial seizures in adults, affecting at least $20 \%$ of all patients with epilepsy [1]. The main features of the TLE may be reproduced in chronic models, such a pilocarpine model. We use the model of pilocarpine because mimics the key features of human TLE $[2,3]$. In this model have been observed high frequency oscillations, called "fast ripples" of 250 to $500 \mathrm{~Hz}$ [4]. These fluctuations play an important role in hippocampal epileptogenesis, acting as generators of pathological synaptic changes in specific brain areas. The pathological interictal activity is considered the cause of seizures and neuronal mechanism responsible of TLE in humans and in experimental models [5]. That is the reason why they are interesting in the study of epilepsy, because they are considered as biomarkers of epilepsy. As part of our results published, we conclude that serotonin has an important role in negative modulation of fast ripples. We found that the concentrations of serotonin in rats with spontaneous seizures were decreased compared to normal rats. The decrease of serotonin in rats with spontaneous seizures is closely related to the emergence seizures. Citalopram administration a selective inhibitor of serotonin re-uptake reduces the occurrence of fast ripples and the amplitude [6]. Also we measurement glutamate concentrations by fluorescence on-line and we could detect glutamate in presence of fast ripples, a fact that was not known, and perform the association of fast ripples and glutamate concentrations. We found that the presence of fast ripples not modified glutamate concentrations significantly, but when clusters of fast ripples were present, glutamate concentrations were increased significantly.

Currently, I have a position as Academic Technical Associate in the laboratory of Neurophysiology and Neurochemistry at the Department of Cell and Molecular Biology of University Center of Biological and Agriculture Sciences in University of Guadalajara, and I belong to the National System of Researchers from Mexico with the appointment of SNI1. Furthermore I advise to Master's and Doctoral students in teaching techniques and skills for scientific biomedical research. And
I'm a professor of Cell Biology field in University of Guadalajara. Actually our working group is focused on developing on-line reading systems for the measurement of glutamate and other neurotransmitters in models of acute epilepsy and asphyxia. Dr. Alberto MoralesVillagrán who is the leader of our working group and who designed the system for on-line detection by fluorescent of different compounds of biological interest, now is working on developing detection systems becoming more sensitive and efficient to implement them in various techniques of neuroscience research, of which we have published two more articles $[7,8]$. With this system detection we can read samples every 200 milliseconds allowing us to evaluate in detail, neurochemical and electrophysiological events in neuronal diseases such as epilepsy, an advantage that cannot be appreciated by chromatography techniques. We obtained interesting results about quantification of glutamate by fluorescence with on-line detection every

200 milliseconds and simultaneously EEG recordings in rats with spontaneous seizures during epileptiform activity induced by pentylenetetrazole (PTZ) administration. The data show a significant increase of glutamate during epileptiform activity and we can correlate the increase with electrical activity during seizures; results that will be published soon. Our challenge is to continue implementing these new reading and detection systems in various experimental models for neuroscience research to provide more detailed information on the development of different neuronal pathologies that allow them to be more efficient and less costly.

\section{References}

1. Babb TL (1999) Synaptic reorganizations in human and rat hippocampal epilepsy. Advances in Neurology 79: 763-779.

2. Medina-Ceja L, Pardo-Peña K Ventura-Mejía C (2014) Evaluation of behaviora parameters and mortality in a model of temporal lobe epilepsy induced by intracerebroventricular pilocarpine administration. NeuroReport 25: 875-879.

3. Curia G, Longo D, Biagini G, Jones SG, Avoli M (2008) The pilocarpine mode of temporal lobe epilepsy. Journal of Neuroscience Methods 172: 143-157.

4. Bragin A, Engel J Jr, Wilson C, Vizentin E, Mathern GW (1999) Electrophysiologic analysis of chronic seizure model after unilateral hippocampal KA injection. Epilepsia 40: 1210-1221

5. Bragin A, Wilson CL, Engel J Jr (2000) Chronic epileptogenesis requires development of a network of pathologically interconnected neuron clusters: a hypothesis. Epilepsia 41: S144-S152.

6. Pardo-Peña K, Medina-Ceja L, Morales-Villagrán A (2014) Serotonin modulates fast ripples activity in rats with spontaneous recurrent seizures. Brain Research 1583: 211-219.

*Corresponding author: Kenia Pardo, Professor, Department of Cell and Molecular Biology, Guadalajara University, Mexico, Tel: 3335961623; E-mail: keny_02pp@hotmail.com

Received October 16, 2015; Accepted October 19, 2015; Published October 29 2015

Citation: Pardo K (2015) Neurotransmitters and Epilepsy. J Epilepsy 1: e103. doi:10.4172/2472-0895.1000e103

Copyright: (c) 2015 Pardo K. This is an open-access article distributed under the terms of the Creative Commons Attribution License, which permits unrestricted use, distribution, and reproduction in any medium, provided the original author and source are credited. 
7. Castro VHC, Valenzuela CLL, Sánchez JCS, Peña KP, Pérez SJL, et al. (2014) An Update of the Classical and Novel Methods Used for Measuring Fast Neurotransmitters During Normal and Brain Altered Function. Current Neuropharmacology 12: 490-508.
8. Ceja LM, Peña KP, Villagrán AM, Ibarra JO, Pérez SL (2015). Increase in the extracellular glutamate levels during seizures and electrical stimulation determined using a high temporal resolution technique. BMC Neuroscience 16 : $1-11$. 